\title{
Cesta básica e assistência social: notas de uma antiga relação
}

\section{The basic food and social assistance: notes from an old relationship}

\author{
Gisele A. Bovolenta \\ Assistente social, mestre e doutora em Serviço Social pela PUC-SP; docente na Fundação \\ Municipal de Ensino Superior de Bragança Paulista (Fesb) — São Paulo, Brasil. \\ gibovolenta@yahoo.com.br
}

\begin{abstract}
Resumo: Este texto busca refletir sobre o papel que a cesta básica vem cumprindo junto à política de assistência social, uma vez que é prevista a criação de um Sistema Nacional de Segurança Alimentar e Nutricional que reconhece a alimentação como um direito humano fundamental, o que permitiria considerar que a provisão de alimentos, de modo regular e frequente, não seria papel da assistência social, tampouco se configuraria como um dos benefícios eventuais dessa área.
\end{abstract}

Palavras-chave: Política de assistência social. Cesta básica. Benefícios eventuais. Sistema Nacional de Segurança Alimentar e Nutricional. Lei de Segurança Alimentar e Nutricional.

\begin{abstract}
This text aims to reflect on the role that the basket has been meeting today with the social welfare policy, since it is envisaged the creation of a National System of Food and Nutritional Security that recognizes food as a fundamental human right, which would allow consider that the provision of food, regular and frequent manner, would not the role of social assistance, nor would be configured as one of the possible benefits of this area.
\end{abstract}

Keywords: Welfare policy. Basket, Benefit. National System of Food and Nutritional Security. Food Security and Nutrition Law.

\section{Introdução}

concessão de alimentos é um dos legados históricos da assistência
social identificada desde as primeiras formas de prestação de auxílios e
que permanece, em grande parte, até os dias atuais como incumbência dessa área. Com viés assistencialista, prover o mínimo necessário à sobrevivência se configurava como um exercício de caridade, cuja esmola reconhecida como o modo mais antigo e presente de amparo ao indivíduo cumpria em grande parte esse papel. 
Nos primórdios do Brasil pertencia ao rei de Portugal o papel de designar esmoleres a fim de recolher espórtulas aos mais necessitados pelas regras da Igreja católica. As várias expressões de ajuda inspiradas nessa prática prestavam auxílio aos miseráveis, permitindo-lhes acesso ao mínimo necessário para a sobrevivência, como alimentos, roupas, medicamentos etc.

"Dar de comer aos famintos" compunha uma das catorze obras de misericórdia ${ }^{1}$ e orientava a prática dos "homens bons", junto às Santas Casas, no exercício da piedade para com os pobres e miseráveis. "A esmola foi a instituição primeira, ao se falar na assistência social colonial. Ela era a forma dos mais ricos exercitarem a caridade e 'ascenderem ao reino dos céus"' (Sposati, 1988, p. 83). Essa prática permitia aos ricos vivenciarem a "paz de consciência" e acomodava a alma cristã em que uns são ricos e outros são pobres; uns são bondosos e ajudam o próximo e outros são humildes e se deixam ajudar pelos "homens bons". 2

Em âmbito legal, foi em 1938 que o Brasil sancionou o Decreto-lei n. 399, que regularizou o salário mínimo e estabeleceu a alimentação mínima a ser garantida ao trabalhador brasileiro. Para tanto, indicou treze itens indispensáveis e que iriam compor o "grupo de alimentos equivalentes aos da ração-tipo", isto é, o conjunto de alimentos mínimos necessários diariamente a um adulto.

A referência aos treze itens - carne, leite, feijão, arroz, farinha, batata, legumes (tomate), pão, café, frutas (banana), açúcar, óleo e manteiga — se baseava em estudos realizados na década de 1930 sobre as necessidades diárias de um adulto em idade laboral, suficientes para seu sustento e bem-estar, e serviu como base para a constituição da cesta básica brasileira.

Na prática, há uma grande diversidade de cestas básicas, ou seja, dos itens que a compõe, algo que varia de cidade, região e estado. No entanto, com base nesses treze itens, o Departamento Intersindical de Estatística e Estudos Socioeconômicos (Dieese) realiza mensalmente, junto a dezesseis capitais brasileiras,

1. A Santa Casa era o lugar da prática da misericórdia. Local onde se desempenhava o compromisso vindo de Lisboa que estabelecia as catorze obras de misericórdia, sendo sete espirituais e sete corporais, as quais estavam em sintonia com os ensinamentos de Santo Tomás de Aquino.

2. Em virtude dos limites que compreendem um artigo, esta reflexão se propõe a abordar apenas a concessão de alimentos no âmbito da proteção social não contributiva (ou distributiva). 
uma pesquisa referente ao custo da cesta básica nacional, comparada com o valor do salário mínimo vigente, que serve como um indicativo que mede o custo de vida e o poder de compra da classe trabalhadora.

No âmbito das políticas públicas, mais precisamente junto à política de assistência social, é possível identificar a presença da cesta básica, como forma de atenção à alimentação, compondo em geral o campo dos benefícios eventuais. ${ }^{3}$ Essa assertiva se confirma ao identificar junto ao Relatório sobre Levantamento Nacional de Benefício Eventual de 2009, do Ministério do Desenvolvimento Social e Combate à Fome (MDS) e Conselho Nacional de Assistência Social (CNAS), que em 91\% dos municípios e Distrito Federal havia a concessão de cesta básica para a situação de vulnerabilidade temporária e em $90 \%$ para as ocorrências de calamidade pública, sendo esta a oferta mais concedida em cada um desses episódios.

Nos Censos Suas de 2010 a 2014 a cesta básica também aparece como a oferta mais concedida em cada ano analisado. Em 2014, 62\% dos Cras atendiam os cidadãos com cesta básica. Junto à gestão estadual ela também apareceu. Alguns estados referenciaram a cesta básica como uma das formas de atenção no campo dos benefícios eventuais, caso do Acre, Amapá e Mato Grosso.

Via de regra, as provisões com cesta básica se dão de maneira permanente e continuada, o que se propõe a indagar se desse modo ela é mesmo um dever da política de assistência social.

Nesse caso, é necessário atentar se a cesta básica não vem cumprindo o papel de amenizar o sofrimento do cidadão diante da ausência de respostas mais efetivas por parte do Estado, na garantia e acesso a direitos socioassistenciais que os protejam e os atendam em suas desproteções sociais. Em outros termos, como a demanda se apresenta, por vezes, complexa, a concessão de cesta básica parece aliviar e confortar as adversidades vividas. Como o Estado se propõe a ser mínimo para a área social, prover alimentação, enquanto indispensável para

3. O benefício eventual é um dos benefícios socioassistenciais sob incumbência da política de assistência social. Está afiançado na Loas de 1993 e, em legislações subsequentes, como atenção para as situações de nascimento, morte, vivência de uma vulnerabilidade temporária e calamidade pública. Trata-se de uma provisão, cujos municípios e os estados federados são responsáveis por sua oferta, numa relação de cooperação quanto à gestão, regulamentação e financiamento. 
a sobrevivência humana, parece ser o lenitivo necessário para que o indivíduo supere por si só a situação vivenciada. Por vezes, o que se observa é uma provisão pontual, isto é, o cidadão não é acompanhado ou mesmo encaminhado em suas necessidades aos serviços socioassistenciais complementares e necessários. É possível afirmar que em muitos casos a atenção do Estado se resuma (quando existente) na provisão de alimentos.

Além disso, nem sempre essas ofertas se encontram regulamentadas, com gestão e financiamento assegurados. Os dados dos Censos Suas de 2014 mostram que $49 \%$ dos municípios tinham os benefícios eventuais regulamentados, o que permite considerar a existência de uma gestão e financiamento incerto e provisório nesse campo de atenção, dado que praticamente metade dos entes municipais não os reconhecem legalmente. Cenário muito parecido ao vivenciado pelos estados federados, quando treze deles e o Distrito Federal estão com esses benefícios regulamentados, conforme o Censo Suas de 2014.

O caráter de eventual desses benefícios, se mal compreendido ou utilizado de modo contrário a sua finalidade, pode contribuir para camuflar violações de direitos que são permanentes na vida do cidadão, apoiando-os na condição de ocasional algo que é, por vezes, constante e duradouro. Nesse sentido, o exemplo da cesta básica é emblemático e representa bem essa realidade, na medida em que os agentes públicos, operadores da política social, a utilizam como resposta às várias demandas existentes.

No estado de São Paulo, formas de atenção a alimentação também se mostram presente junto à Secretaria de Desenvolvimento Social (Seds — responsável pela política de assistência social em âmbito estadual). É o caso dos programas Bom Prato e Viva Leite. No site da Seds, o programa Bom Prato é apresentado como sendo de segurança alimentar, voltado para garantir alimentação saudável à população de baixa renda. Da mesma forma, o programa Viva Leite se propõe a distribuir leite pasteurizado a crianças e idosos em situação de insegurança alimentar e vulnerabilidade social. Ou seja, são formas de atenção que se enquadrariam mais no campo da segurança alimentar do que da própria assistência social.

Na cidade de São Paulo, a alimentação, na forma de cesta básica, compõe o campo dos benefícios eventuais ofertados nos atendimentos dos Centros de Referências da Assistência Social (Cras), contando com legislação municipal 
desde 2009 (Portaria n. 44). No entanto, a incapacidade de acolher todas as solicitações cria, no trato desses benefícios, uma relação perversa e desumana entre o profissional e o usuário, muito longe de uma relação cidadã, quando se delega ao profissional, diante da negligência e omissão do poder público, "escolher ou selecionar" as situações de desproteções mais miseráveis a ser atendidas dentre tantas necessidades apresentadas.

Ou seja, essa reflexão propõe pensar sobre o papel e a presença da cesta básica junto à política de assistência social, a partir da realidade da cidade de São Paulo, principalmente tomando por base que desde 2006 há uma legislação própria para garantir a alimentação como um direito humano fundamental (Lei Orgânica de Segurança Alimentar e Nutricional — Losan, Lei n. 11.346), e não como um paliativo diante das demandas complexas que cotidianamente recorrem à assistência social em busca de proteção social.

\section{A alimentação como um direito humano fundamental e universal}

Ao reconhecer que a alimentação é um direito fundamental em si, não existe, portanto, a necessidade de sua concessão estar entremeada por outras áreas, como vem ocorrendo em grande parte com a política de assistência social.

É preciso lembrar que desde 2006, a partir da Lei Orgânica de Segurança Alimentar e Nutricional - Losan (Lei n. 11.346), que propõe construir um Sistema Nacional de Segurança Alimentar e Nutricional (Sisan), a alimentação passou a ser reconhecida como um direito fundamental da Constituição federal (Emenda Constitucional n. 64/2010). Com base nos princípios da participação social e intersetorialidade, o Sisan, por meio de diversos setores governamentais e da sociedade civil, busca promover, em todo o país, o Direito Humano a Alimentação Adequada (DHAA), através da promoção, formulação e articulação de diversas ações e programas da Política Nacional de Segurança Alimentar e Nutricional (PNSAN), bem como o monitoramento e a avaliação da situação alimentar e nutricional da população brasileira.

Segundo dados da Organização das Nações Unidas para Alimentação e Agricultura (FAO), em 2014 o Brasil teria saído do Mapa da Fome Mundial, 
o que ocorreu a partir de um conjunto de ações que foram apresentados no Mapeamento de Segurança Alimentar e Nutricional (Mapasan) realizado em 2014 no país pelo MDS. ${ }^{4}$

Os resultados alcançados se devem a um conjunto de medidas em diferentes setores, como a ampliação do poder de compra do salário mínimo, o aumento do acesso ao emprego, o fortalecimento dos programas de transferência de renda às famílias de baixa renda, a consolidação dos sistemas universais de educação e saúde, a ampliação do Programa Nacional de Alimentação Escolar e o fortalecimento dos programas de agricultura familiar no país. (Brasil, 2015, p. 14)

O reconhecimento da alimentação (adequada) enquanto um direito intrínseco à condição humana, assegurou uma área específica e própria para garantir seu acesso. De modo mais amplo, significa considerar que não é somente por meio da cesta básica que o cidadão tem seu direito assegurado. Ações mais amplas, concretas e intersetoriais devem compor o campo da Segurança Alimentar e Nutricional (SAN), como a realização de programas e políticas dessa área, monitoramento das ações realizadas a partir, por exemplo, da agricultura familiar (compras institucionais e Programa de Aquisição de Alimentos), da convivência com o semiárido - acesso à agua, do Programa de Aquisição de Alimentos (PAA), do Programa Nacional de Alimentação Escolar (PNAE), da Segurança Alimentar e Nutricional junto ao Sistema Prisional e às instituições de longa permanência.

Outras ações também podem ser fomentadas por meio das Câmaras Intersetoriais de Segurança Alimentar e Nutricional (Caisan), instâncias que coordenam os órgãos públicos responsáveis pela execução da política, construídas nas Conferências e nos Conselhos de Segurança Alimentar e Nutricional (Consea), a fim de garantir a participação da sociedade civil na elaboração de diretrizes para a execução da Política Nacional de Segurança Alimentar e Nutricional. Como

4. O objetivo foi levantar informações acerca de diferentes aspectos do Sisan, sendo realizado pela Secretaria Nacional de Segurança Alimentar (Sesan) e Secretaria de Avaliação e Gestão de Informação (Sagi). A partir de um questionário eletrônico, gestores municipais, estaduais e do Distrito Federal puderam responder sobre a identificação e caracterização dos órgãos gestores da Política de Segurança Alimentar e Nutricional (SAN), das institucionalidades do controle social estabelecido e da disponibilidade de equipamentos públicos nessa área. 
exemplo, conforme o Mapasan: apoio logístico para transporte de alimentos produzidos por agricultores familiares; assistência técnica e extensão rural para agricultura familiar (Ater); doação de alimentos, cestas de alimentos ou subsídios aos alimentos (industrializados, em grãos ou in natura); capacitação, fomento ou incentivo à produção agroecológica; ações de educação alimentar e nutricional; apoio às práticas de agricultura urbana; implantação de cisternas para acesso à água. Além da construção de restaurantes populares, cozinhas comunitárias, abastecimento, distribuição e comercialização de alimentos a partir dos bancos de alimentos.

Há, portanto, um conjunto de ações a ser desenvolvido que compreende a alimentação de modo mais amplo, ou seja, como um direito humano fundamental, o que contribui para a defesa de que não é dever da assistência social a concessão de cesta básica, como garantia alimentar permanente e contínua. Em outros termos, deve-se destacar que há uma política reconhecida nacionalmente que assegura a alimentação como um direito de todos os cidadãos, delegando ao Estado o dever de assegurá-la. Trata-se de uma área própria, com suas especificidades e atribuições, que não requer subordinação e/ou ingerência de outras áreas sociais.

No entanto, os números do Mapasan ${ }^{5}$ mostram que o reconhecimento da alimentação, enquanto área própria de ação, ainda requer empenho e dedicação, a fim de consolidar-se plenamente. Embora todos os estados da federação tenham declarado possuir Câmaras Intersetoriais de Segurança Alimentar e Nutricional (Caisan) estruturadas, as quais buscam coordenar os órgãos públicos responsáveis pela execução da política, apenas 25\% das Unidades Federativas (Bahia, Distrito Federal, Espírito Santo, Minas Gerais, Mato Grosso do Sul) dispõem de recursos exclusivos para suas ações.

A maior parte dos estados e o Distrito Federal já formalizaram os seus Sistemas de Segurança Alimentar e Nutricional (Sisan) por meio de lei. Apenas os estados do Acre, Mato Grosso e São Paulo ainda não publicaram suas respectivas leis estaduais de Segurança Alimentar e Nutricional. Além disso, somente os estados de Minas Gerais, Pernambuco, Ceará, Paraná, Santa Catarina e Maranhão e o DF relataram ter planos de Segurança Alimentar e Nutricional.

5. Dos 26 estados mais Distrito Federal, 23 contribuíram com informações para este levantamento (exceto Amapá, Goiás e Rio Grande do Norte). No caso dos municípios, foram 1.628 respondentes. 
No caso dos municípios, 181 declaram possuir câmaras intersetoriais; destes, apenas $10 \%$ dispõem de recursos orçamentários para a gestão de suas ações; $81 \%$ não possuem receita própria e $9 \%$ não souberam responder sobre sua real situação. Tomando por base que há no Brasil atualmente 5.570 municípios, esses números ainda se mostram bastante inexpressivos.

Por fim, é interessante observar que a esfera federal ainda é a instância que mais investe nos restaurantes populares, com $46 \%$, seguida dos municípios, com $17 \%$, e dos estados, com $13 \%$, além de outras combinações: $8 \%$, município e MDS; $4 \%$, município e estado; $2 \%$, estado e MDS; $3 \%$, iniciativa privada; $1 \%$, município e iniciativa privada; e $6 \%$, outras maneiras. As cozinhas comunitárias ofertam refeições em regiões de maior vulnerabilidade e são previstas como ações do Sistema Nacional de Segurança Alimentar e Nutricional; 37\% das cozinhas comunitárias também são financiadas pelo MDS; os estados federados financiam 4\%. Além disso, o MDS também é o maior financiador dos Bancos de Alimentos, em $43 \%$ dos dados apresentados.

Se levarmos em conta que a alimentação é uma área própria de ação, essa contradição permanece sendo reproduzida pelo próprio órgão que coordena a política de assistência social em âmbito nacional. Na execução orçamentária do MDS em 2014, dos R \$ 68.607.635.321,00 destinados a essa pasta, $\mathrm{R} \$ 2.518 .170 .390,00$ foram assegurados à Secretaria Nacional de Segurança Alimentar (Sesan). Ou seja, a alimentação permanece mantendo relações bem próximas com a assistência social, dificultando seu reconhecimento enquanto área própria de ação que requer, inclusive, receita específica em sua gestão e execução. Além disso, não deve permanecer utilizando ou subtraindo recursos, estrutura e gestão da assistência social para atividades e ações que, a rigor, não são da alçada da área de segurança alimentar.

Ao conceber e defender ainda que a alimentação é um direito humano fundamental, é preocupante admitir que, em pleno terceiro milênio, há famílias e/ou indivíduos que ainda sejam vítimas da fome ou sem acesso a uma alimentação adequada, apesar dos avanços apontados pelo Mapeamento de Segurança Alimentar e Nutricional (Mapasan) de 2014.

A realidade desigual vivenciada por centenas de brasileiros aponta exemplos de que a fome ainda compõe o nosso cenário. Isso pode ser observado, 
por exemplo, em matéria jornalística apresentada pelo jornal Folha de S.Paulo, denunciando que em Tocantins, "um dos maiores celeiros de grãos do país, o Estado viu seu número de milionários crescer $510 \%$ na última década, mas 172 mil famílias ainda passam fome" (Massuela e Rangel, 2015). O sucesso do agronegócio contrasta com a realidade de centenas de famílias, em grande parte descendentes de escravos, que sofrem dificuldades diárias para garantir seu sustento. Segundo a reportagem, antes da expansão das fazendas era possível plantar alimentos para a subsistência dos nativos, porém, com a redução do espaço, a agricultura familiar e o extrativismo tradicional foram (e estão) bastante comprometidos.

É papel do Estado, de modo incondicional, garantir alimentação a todos os cidadãos do país, seja via redução da taxação de impostos sobre os itens básicos de subsistência (que em geral compõem a cesta básica), ${ }^{6}$ seja garantindo equipamentos e serviços que atendam e/ou amenizem a fome, permitindo o acesso diário a alimentação, como asseguradas no campo da Segurança Alimentar e Nutricional. Ações que compreendem que a alimentação não é uma atenção eventual, mas permanente e contínua, considerando que o ser humano precisa se alimentar todos os dias de sua vida, durante todo o ano, o que requer uma atenção estruturada e integrada no porte de uma política pública. Essas considerações permitem compreender e defender que nesses moldes a cesta básica não é parte dos benefícios eventuais da política de assistência social, apesar de sua expressiva presença nessa área.

\section{A provisão de alimentos pela assistência social na cidade de São Paulo}

Ao se aproximar de uma dada realidade é possível identificar as assertivas que este texto se propõe destacar. Na cidade de São Paulo atualmente essa oferta

6. Quanto a isso, em 2013 o governo federal desonerou impostos sobre itens que compõem a cesta básica, zerando a incidência de PIS/Pasep-Cofins e de IPI de dezesseis itens: carnes (bovina, suína, aves e peixes), arroz, feijão, ovo, leite integral, café, açúcar, farinhas, pão, óleo, manteiga, frutas, legumes, sabonete, papel higiênico e pasta de dentes. A partir dessa medida anunciada, o governo abriu mão de R \$7,3 bilhões em impostos ao ano, dos quais R $\$ 6,8$ bilhões relativos a PIS/Cofins e R $\$ 572$ milhões relativos a IPI. Somente em 2013, a renúncia fiscal foi de R $\$ 5,5$ bilhões, segundo as contas do governo (Mendes, 2013). 
compõe o campo dos benefícios eventuais, regulamentado em âmbito municipal pela Portaria n. 44 de 2009, tendo, por sua vez, um histórico de atenção que se aproxima da instituição do programa Atendimento a Populações com Problemas Agudos de Subsistência (Appas), ${ }^{7}$ instituído em 1972, que atribuía ao poder público municipal uma parcela de responsabilidade sobre a demanda da população marginalizada. ${ }^{8}$

Esse programa se baseava no contexto socioeconômico da década de 1970, quando se registrava que a metrópole paulistana era o mais dinâmico centro de desenvolvimento econômico do país, com cerca de 6 milhões de habitantes, saltando para 8 milhões se considerada toda a região metropolitana. Estimava-se que, na época, $30 \%$ da população encontrava-se socialmente marginalizada, formada por famílias numerosas e com renda insuficiente para prover condições mínimas de subsistência.

Por meio dos convênios com entidades particulares, o atendimento voltava-se para orientações psicossociais, encaminhamentos e fornecimento de auxílios financeiros para indivíduos e famílias avaliados com problemas agudos de subsistência. Tais auxílios, via de regra, atendiam as necessidades de alimentação; transporte para locomoção ou caminhão para mudança, em razão de família com ordem de despejo; pagamento de terreno em via de perda; pagamento de aluguel; pagamento de prestação, de instrumental para exercer a profissão; documentação e outras atenções identificadas como necessárias após a avaliação profissional.

A compreensão vigente na época reconhecia que o indivíduo era o principal agente transformador de sua realidade, o que compunha a metodologia das ações desenvolvidas pelo profissional que o atendia. Nesse sentido, buscava-se

7. Nos documentos analisados são identificados termos diferentes para referir-se ao Appas. Ora ele aparece como projeto, ora como programa ou ainda como uma atividade. Os vários termos usados na narrativa desta memória preservam o termo conforme a referência utilizada. Em alguns documentos também se observa a ocultação do termo "agudos" de Appas, reduzindo-o para APPS.

8. Esse programa é fruto do anteprojeto elaborado em 1971, intitulado Descentralização de Atendimento Individualizado de Marginalização Aguda. Ele se baseou tanto nas necessidades identificadas pela experiência de trabalho desenvolvida por diversos órgãos públicos e particulares como também em dados apontados pelo Plano Urbanístico Básico e Plano de Amparo Social. No entanto, o atendimento de modo regionalizado nos moldes previstos nesse projeto já existia desde 1967, isto é, há cinco anos, quando o Appas foi de fato instituído (Prefeitura de São Paulo, 1972). 
estimular a participação ativa do indivíduo na superação de seus problemas, oferecer mudanças ao mesmo, no sentido de sua autopromoção e atuar, a partir de uma perspectiva de globalidade, na realidade urbana.

É interessante destacar que o entendimento por "caso agudo de subsistência" era aquele em que a atenção supletiva por tempo previamente determinado no plano de tratamento (em média, de quatro a seis meses) poderia tirar o indivíduo da situação vivenciada. Isso se dava de modo diferente dos casos considerados "crônicos", como, por exemplo, mendicância, idosos, inválidos e migrantes, que não se enquadravam nos objetivos do programa por precisarem de atenções mais complexas e permanentes, as quais se estenderiam por mais tempo que o previsto pelo tratamento dispensado pelo programa.

Em 1973, o município de São Paulo contava com treze postos de atendimento do programa Appas. Por meio de um estudo socioeconômico realizado nesse mesmo ano pelo Departamento de Integração Social da Secretaria de Bem-Estar Social (Sebes), observou-se que $67 \%$ dos casos - que correspondia a 1.564 casos atendidos entres os meses de outubro a dezembro de 1972 — não haviam sido matriculados para fins de atendimento, em razão de recursos insuficientes diante da demanda, em decorrência de serem caracterizados como crônicos ou ainda devido às solicitações que não se enquadravam nos objetivos do programa. Ou seja, o número de pessoas de fato atendidas correspondia a menos da metade da demanda que procurava alguma forma de atenção. O estudo mostrou, por fim, que os casos mais atendidos eram voltados para alimentação, saúde, documentação, prestação de terreno em atraso e aluguel atrasado (Secretaria de Bem-Estar Social, 1973).

No entanto, no caso da alimentação, esse relatório apresentou que o consumo, por uma família composta por quatro a seis pessoas, tinha duração estimada de uma semana, o que mostra que na maior parte do mês a família ainda era a maior responsável por manter suas necessidades alimentares.

No relatório sobre benefícios eventuais da Prefeitura de São Paulo, realizado pela Secretaria Municipal de Assistência Social (SAS) (Prefeitura de São Paulo, 2002), também se reconhece a aproximação desse programa dos benefícios eventuais. O próprio documento, em seu início, relata que o trabalho apresentado refere-se ao serviço de prestação continuada da Secretaria de 
Assistência Social, denominado Atendimento a População com Problemas de Subsistência (Appas) ou Centro de Referência, no qual são concedidos benefícios eventuais à população. Ou seja, a SAS tinha um serviço de atendimento denominado Appas que concedia benefícios eventuais, dentre eles a cesta básica, ainda que não fosse sob essa nomenclatura.

As ofertas dispensadas como benefícios eventuais eram (e algumas ainda são) cestas básicas, óculos, próteses, órteses, medicamentos, passagens, auxílios para documentação, dentre outros, sendo previstos ainda auxílios nas situações de calamidade pública. ${ }^{9}$

Em abril de 2002 foram registradas 12.805 solicitações junto aos postos do Appas, tendo sido, de fato, atendidos 3.484 benefícios, o que corresponde a pouco mais de $27 \%$ da necessário. Esses dados ilustram a capacidade limitada de atenção desses postos diante da demanda existente.

$\mathrm{O}$ volume de cestas distribuídas apresentado nesse relatório mostrava que 4 mil unidades/mês foram destinadas aos postos de atendimentos Appas e mil unidades destinavam-se às situações de emergência, o que somava um montante de 5 mil unidades/mês, registrado no ano de 2002.

No relatório de gestão 2001-4 da Secretaria Municipal de Assistência Social (SAS) (Prefeitura de São Paulo, 2004), os benefícios eventuais são apresentados como uma das funções do Cras para situações de emergência, calamidade pública e necessidades circunstanciais consideradas de risco pessoal e social, concedidos na forma de auxílios materiais e pagamento de serviços (como fotos, passagens etc.).

No caso de atenção a situações de emergência e calamidade pública, esse relatório apresenta que a SAS desenvolveu um trabalho articulado junto a outras secretarias, sob a coordenação da Defesa Civil, no socorro imediato às vítimas. No ano de 2004 foi registrado o atendimento a 11.884 famílias, o que corresponde a 42.351 pessoas vítimas de enchentes, deslizamentos, riscos

9. Além da alimentação, grande parte dos recursos desses postos destinava-se a provisões da área da saúde, realidade que o CNAS buscou mudar ao editar em 2010 a Resolução n. 39, que dispõe sobre o processo de reordenamento dos benefícios eventuais no âmbito da política de assistência social em relação à política de saúde. Trata-se de um momento em que várias provisões foram reconhecidas como não sendo incumbência da assistência social. 
de desabamentos etc. ${ }^{10}$ Esses atendimentos concentraram-se entre os meses de janeiro a março, período das chuvas de verão, atingindo em maior número a população das zonas Leste e Sul da cidade.

No Plano de Assistência Social da Cidade de São Paulo (Plas-SP), 2002-3 é atestado que "os benefícios operados por SAS não foram até hoje submetidos a uma legislação de direitos e deveres (previsto na Loas como benefícios eventuais) ou mesmo da direção de cobertura universal" (Prefeitura de São Paulo 2003), reconhecendo que isso é um desafio para operar uma política de direitos. Esse relato mostra que até 2003 a cidade de São Paulo ainda não contava com a regulamentação dos benefícios eventuais nem mesmo com sua cobertura universal.

Em 2006, o Plas reconheceu os benefícios eventuais em duas frentes: uma relacionando-os à emergência, de modo que o cidadão fosse atendido em decorrência dessa situação, cuja meta proposta era manter estoques suficientes conforme solicitado; e outra os apresentavam enquanto parte das ações do Cras, ofertados por meio de fotos, instrumental de trabalho, passagem intermunicipal para busca de trabalho e interestadual para retorno à cidade de origem, alimentação etc.

No Plas 2009-12 e 2014-7 não há referências aos benefícios eventuais. Em ambos há uma seção de Gestão de Benefícios e Transferência de Renda, compreendendo, ao que parece, benefícios como transferência de renda.

Em relação ao montante de ofertas concedidas atualmente, o Observatório Social da Secretaria Municipal de Assistência e Desenvolvimento Social (SMADS) forneceu alguns dados que mostravam a provisão de benefícios

10. A cidade de São Paulo conta atualmente com uma Coordenadoria de Atendimento Permanente e de Emergência (Cape) que, após notificação da Defesa Civil sobre a ocorrência de uma emergência ou identificação de uma situação de calamidade pública, atua na promoção, apoio e proteção à população atingida, com atenções e provisões materiais, conforme as necessidades detectadas. A Cape assegura, ainda, a realização de articulações e a participação em ações conjuntas de caráter intersetorial para a minimização dos danos ocasionados, além do provimento das necessidades identificadas. Esse serviço está normatizado pela Portaria n. 33 da Secretaria Municipal de Assistência e Desenvolvimento Social (SMADS) de 2010. Sua criação ocorreu em 1999, inicialmente com o nome de Central de Atendimento Permanente (CAP), funcionando como um serviço de plantão 24 horas para as pessoas vítimas de emergência. 
eventuais por cada Cras do município durante todo o ano de 2014. A síntese desses dados é observada no Quadro I. ${ }^{11}$

Quadro I - Quantidade total de BE concedido em 2014 entre todos os Cras em São Paulo

\begin{tabular}{|l|c|}
\hline BE & Quantidade \\
\hline Alimentação & 16.794 \\
\hline Alimentação para viagem & 126 \\
\hline Transporte urbano & 533 \\
\hline Pagamento de contas & 503 \\
\hline Foto/fotocópia & 285 \\
\hline Pequeno reparo/moradia & 133 \\
\hline $2^{\text {a via de documentos }}$ & 627 \\
\hline Instrumento de trabalho & 188 \\
\hline Passagem intermunicipal/estadual & 286 \\
\hline Outros & 79.482 \\
\hline TOTAL BE & \\
\hline
\end{tabular}

Fonte: Informações obtidas junto ao Observatório Social da PMSP. Cf.

Dados de Execução, 2014. Elaboração: COPS/CMA/out.2015.

$\mathrm{Na}$ cidade de São Paulo, a maior atenção no campo dos benefícios eventuais concentra-se em alimentação, o que representou mais de $86 \%$ das ofertas durante o ano de 2014. Das sete ofertas concedidas na categoria de "Outros", duas referem-se a colchões para frentes frias ofertadas pelo Cras Aricanduva e cinco não foram especificadas, mas foram concedidas no Cras Marsilac.

A quantidade de benefícios para alimentação, materializados por meio da cesta básica, é concedida aos Cras conforme a demanda apresentada. Essa informação não se encontra descrita em nenhum dos documentos analisados e

11. Informações mais detalhadas sobre o BE, como número de atendimentos por Cras, por tipo de benefício, valores e procedimentos dessa atenção, não constam no Plas 2014-7 nem no site da prefeitura e não foram identificadas em nenhum canal de informação. Assim, tais dados foram solicitados ao Serviço de Informação ao Cidadão (SIC) da Prefeitura de São Paulo, via Lei de Acesso à Informação (Lei Federal n. 12.527/11). 
foi objeto de investigação junto à Smads/Observatório Social, a qual fez essa afirmação, e que o processo de escolha e composição das cestas se dá via processo de licitação. Quanto aos demais benefícios, a informação concedida foi: "Verificar na Norma Técnica dos Serviços Socioassistenciais - Instrumentais".

Esse documento de 2012 tem o intuito "de estabelecer padrão técnico para a execução dos serviços socioassistenciais, trazendo um conjunto de normatizações em consonância ao que preceitua a PNAS e a NOB-Suas". Nele, a concessão dos benefícios eventuais está atrelada à inserção da família no PAIF (em ações de atendimento ou acompanhamento social) ou em serviço da rede socioassistencial. Esses benefícios compõem as seguranças de sobrevivência a riscos circunstanciais executadas pelos CRAS, sendo que sua concessão é reconhecida como uma das atribuições dos Centros de Referência de Assistência Social do município.

É expressivo observar que mais de $86 \%$ das ofertas na cidade de São Paulo no campo dos benefícios eventuais da política de assistência social concentram-se em alimentação. Primeiro porque se entende que esse é um campo da Segurança Alimentar e Nutricional, havendo inclusive legislações que preveem um conjunto de ações nessa área, conforme foi brevemente narrado. Em segundo lugar, porque a oferta de alimento pode ser uma estratégia para o Estado, no caso o município de São Paulo, atender o indivíduo sem responder de fato pela demanda que ele apresenta, uma vez que, por vezes, são demandas complexas, e a concessão de uma cesta básica pode ser um artifício para o órgão público camuflar sua omissão e negligência.

Não é apenas na cidade de São Paulo que a cesta básica ocupa lugar expressivo. Quando se observam os dados nacionais, como os do Censo Suas ou do Relatório sobre o Levantamento Nacional de Benefícios Eventuais, conforme já apontado, ela também aparece em destaque, algo que pode ter um comportamento similar à realidade paulistana: ser um lenitivo às demandas complexas que exigem ações mais profundas por parte do poder público.

Quando se analisa cada um dos Cras no município de São Paulo, a alimentação é o benefício mais concedido. Em 2014 todos os Cras ofereceram a alimentação, exceto os de Campo Limpo, Capão Redondo e Jardim Ângela, que não concederam nenhum BE para alimentação ou qualquer outra modalidade 
de atenção. Essa identificação é muito inquietante, uma vez que são distritos com altos índices de vulnerabilidade e risco social, cujos cidadãos supostamente podem ter vivido situações esporádicas ao longo do ano que requeriam suporte e apoio por parte do poder público.

A Zona Norte de São Paulo, composta por quinze Cras, foi a região onde mais se concedeu cesta básica, 36\%; seguida pela Zona Leste, com dezessete Cras e $33 \%$; depois a Zona Sul, com quinze Cras e $25 \%$ de cestas concedidas; a Zona Oeste, três Cras e 4\%; e o Centro, com um Cras e 2\% do total de cestas básicas fornecidas. O Cras da Freguesia do Ó foi onde mais se concedeu cesta básica em 2014: novecentas ao longo do ano.

Em 2013 foi instituída, pela Secretaria Municipal de Assistência e Desenvolvimento Social (SMADS), a Ordem Interna n. 01, a qual trouxe orientações na concessão dos benefícios eventuais conforme as recomendações do Tribunal de Contas do Município de São Paulo, mantendo na prática as mesmas provisões já existentes e sem o reconhecimento trazido pela Loas do auxílio-natalidade e auxílio-funeral como provisões voltadas às famílias em virtude dessas ocorrências.

Além disso, não há uma relação de cooperação entre o município de São Paulo e o estado paulista na provisão dos benefícios eventuais, conforme prevê a Loas em seu art. 22 e nas legislações subsequentes. Esse reconhecimento exemplifica a relação desequilibrada entre os entes federados na gestão pública e mostra a necessidade de revisão do Pacto Federativo no âmbito da política de assistência social e, em específico, no caso desses benefícios. Na prática, a cidade de São Paulo tem mantido sozinha uma responsabilidade que não é só dela, mas é também do estado paulista, o qual não coopera com a provisão desses benefícios em nenhum dos 645 municípios do estado.

Ou seja, a maior cidade do país exemplifica a realidade que aparece nas pesquisas nacionais, ao centrar os benefícios eventuais no campo da alimentação, reconhecendo aqui que essa não é uma necessidade eventual, como caracteriza essa forma de benefício, mas sim um direito humano fundamental, com suas especificidades e área própria, sem necessidade de intermediações por parte da política de assistência social. E mais: a centralidade em torno da alimentação pode ser um indicativo de ausência de respostas mais efetivas, um meio pelo qual o poder público se omite, esconde e negligencia os reais direitos do cidadão. 


\section{Considerações finais}

Esta breve reflexão tem por intuito pensar o papel que a alimentação vem cumprindo junto à política de assistência social, sobretudo considerando a existência de um campo próprio que reconhece a alimentação como um direito humano fundamental: a Segurança Alimentar e Nutricional.

A compreensão defendida aqui é que a alimentação, enquanto uma atenção permanente e contínua, não se configura como um campo próprio da assistência social. Enquadrada em geral no campo dos benefícios eventuais, ela contraria a própria finalidade desse benefício em ser uma atenção esporádica, provisória, ocasional, pontual, diante de uma situação de eventualidade vivida pelo cidadão, que na Loas foi caracterizada em virtude do nascimento, morte, vivência de uma vulnerabilidade temporária e calamidade pública.

O reconhecimento da Lei Orgânica de Segurança Alimentar e Nutricional (Losan), bem como sua implementação e efetivação, pode contribuir no sentido de direcionar a cada área o que de fato lhe compete.

No âmbito da assistência social seria possível, sim, pensar a provisão de alimentos em casos esporádicos, como diante de uma calamidade pública ou uma emergência, por exemplo. No entanto, em geral não é isso que ocorre. A alimentação possui muitas vezes uma atenção permanente, ou seja, são quase sempre as mesmas famílias atendidas diante de uma situação de vulnerabilidade social.

Nesse caso, vale a pena pontuar que uma situação de vulnerabilidade social é diferente de uma situação de vulnerabilidade temporária, associando a primeira com a ideia de condição e a segunda como um evento, um fato. No caso dos benefícios eventuais, estes não são provisões perante a vivência contínua de vulnerabilidade, ainda que essa possa também acarretar episódios inesperados que requeiram provisão e proteção estatal. É preciso demarcar a diferença entre a vivência permanente da situação de vulnerabilidade e a temporariedade atribuída a esse contexto em virtude de um episódio específico.

Mesmo porque o enfrentamento e a superação da situação de vulnerabilidade social precisam contar com um campo de proteção social mais amplo e estruturado, composto por bens e serviços materializados por meio dos programas, projetos, benefícios e equipamentos das várias políticas públicas. 
A aproximação com a realidade do município de São Paulo permitiu pensar como a alimentação ainda se encontra muito presente junto à política de assistência social; como sua concessão pode estar associada às várias omissões do Estado. Uma relação historicamente entremeada que não foi plenamente superada mesmo no advento dos direitos. Nesse caso, parece que a ação estatal permanece limitada a "dar de comer aos famintos"!

\section{Recebido em 4/8/16 - Aprovado em 13/6/17}

\section{Referências bibliográficas}

BOVOLENTA, Gisele Aparecida. O beneficio eventual da Loas como garantia de proteção social. Tese (Doutorado em Serviço Social) — Pontifícia Universidade Católica de São Paulo (PUC-SP), São Paulo, 2016.

BRASIL. Lei n. 12.435, de 6 de julho de 2011. Diário Oficial da União, Brasília, DF, 7 jul. 2011. Disponível em: <http://www.planalto.gov.br/ccivil_03/_Ato2011-2014/2011/ Lei/L12435.htm>. Acesso em: 30 jul. 2015.

. Ministério do Desenvolvimento Social e Combate à Fome. Conselho Nacional de Assistência Social. Resolução n. 39, de 9 de dezembro de 2010. Diário Oficial da União, Brasília, DF, 16 dez. 2010. Disponível em: <http://conselho.saude.gov.br/ ultimas_noticias/2011/relatorio/resolucao_cnas_39.pdf $>$. Acesso em: 20 abr. 2015.

. Política Nacional de Assistência Social - PNAS/2004. Ministério do Desenvolvimento Social e Combate à Fome; Secretaria Nacional de Assistência Social, Brasília: 2004.

. Ministério do Desenvolvimento Social e Combate à Fome. Mapasan 2014: Mapeamento de Segurança Alimentar e Nutricional. Brasília: MDS. Secretaria de Avaliação e Gestão de Informação; Secretaria Nacional de Segurança Alimentar e Nutricional. 2015.

. Ministério do Desenvolvimento Social de Combate à Fome; Secretaria Nacional de Assistência Social; Departamento de Benefícios Assistenciais. Relatório sobre o 
levantamento nacional de benefícios eventuais. Brasília, 2009. Disponível em: $<\mathrm{http} / / /$ www.cogemas.pr.gov.br/arquivos/File/Documento/Relatorio_BE_Final.pdf $>$. Acesso em: 30 maio 2015.

MASSUELA, Amanda; RANGEL, Anna. No Tocantins, há fome enquanto número de milionários cresce 510\%. Folha de S.Paulo, editoria de treinamento, 7 jun. 2015. Disponível em: <http://www1.folha.uol.com.br/mercado/2015/06/1638650-notocantins-populacao-passa-fome-enquanto-numero-de-milionarios-cresce-510-em-dezanos.shtml>. Acesso em: 7 jun. 2015.

MENDES, Priscilla. Dilma anuncia na TV desoneração de produtos da cesta básica. G1, Brasília, 8 mar. 2013. Disponível em: <http:/g1.globo.com/economia/noticia/2013/03/ dilma-anuncia-na-tv-desoneracao-total-de-produtos-da-cesta-basica.html $>$. Acesso em: 13 jun. 2015.

PREFEITURA DE SÃO PAULO. Departamento de Integração Social. Atendimento a Populações com Problemas Agudos de Subsistência (Projeto). [São Paulo], 1972, p. 6. Acervo - Biblioteca Espaço Público do Aprender Social (Espaso) da Secretaria de Assistência e Desenvolvimento Social de São Paulo.

. Secretaria Municipal de Assistência Social. Benefícios eventuais — relatório [s.n.], 2002.

. Plano de Assistência Social da Cidade de São Paulo - PLASsp 2002-2003. São Paulo: [s.n.], 2003, p. 66.

. Relatório de gestão 2001-2004. São Paulo: [s.n.], 2004.

. Secretaria Municipal de Assistência e Desenvolvimento Social. Norma técnica dos serviços socioassistenciais: proteção social básica. São Paulo: [s.n.], 2012. p. 7.

SECRETARIA DE BEM-ESTAR SOCIAL. Departamento de Integração Social (Equipe de supervisão: Alcione H.Borner; Marina R.Tirico; Sônia Gafonovitch; YayoiYamane). Estudo socioeconômico do programa A.P.P.A.S. [São Paulo], 11 jun. 1973. Acervo Biblioteca Espaço Público do Aprender Social (Espaso).

SPOSATI, Aldaíza. Vida urbana e gestão da pobreza. São Paulo: Cortez, 1988. 